\title{
Synthetic Cannabinoids: Pharmacology, Behavioral Effects, and Abuse Potential
}

\author{
Sherrica Tai • William E. Fantegrossi
}

Published online: 15 March 2014

(C) Springer International Publishing AG 2014

\begin{abstract}
Cannabis has been used throughout the world for centuries. The psychoactive effects of cannabis are largely attributable to $\Delta^{9}$-tetrahydrocannabinol $\left(\Delta^{9}\right.$-THC), the prototypical cannabinoid that occurs naturally in the plant. More recently, chemically and pharmacologic-distinct synthetic cannabinoids (SCBs) have emerged as drugs of abuse. Compared with $\Delta^{9}$-THC, the distinct structures of these compounds allow them to avoid legal restrictions (at least initially) and detection in standard drug screens. This has contributed to the popularity of SCBs among drug users who seek to avoid positive drug screens. Importantly, the distinct structures of the SCBs also typically result in increased affinity for and efficacy at cannabinoid $\mathrm{CB} 1$ receptors, which are thought to be responsible for the psychoactive effects of $\Delta^{9}$-THC and its analogues. Accordingly, it seems likely that these more powerful cannabimimetic effects could result in increased adverse reactions and toxicities not elicited by $\Delta^{9}$-THC in cannabis. Animal models useful for the study of emerging SCBs include the cannabinoid tetrad, drug discrimination, and assays of tolerance, dependence, and withdrawal. However, these in vivo procedures have not been particularly informative with regards to drug efficacy, where the majority of SCB effects are comparable with those of $\Delta^{9}$-THC. In contrast, essentially all in vitro measures of drug efficacy confirm $\Delta^{9}$-THC as a relatively weak CB1 partial agonist, whereas the majority of the SCBs detected in commercial preparations are full agonists at the $\mathrm{CB} 1$ receptor. As use of these emerging SCBs continues to rise, there is an urgent need to better understand the pharmacology and toxicology of these novel compounds.
\end{abstract}

S. Tai $\cdot$ W. E. Fantegrossi $(\square)$

Department of Pharmacology and Toxicology, College of Medicine,

University of Arkansas for Medical Sciences, 4301 W. Markham

Street - Mail Slot 638, Little Rock, AR 72205-7199, USA

e-mail: WEFantegrossi@uams.edu
Keywords Cannabis - Synthetic cannabinoids · SCBs · THC $\cdot$ Psychoactive effects $\cdot$ CB1 receptors

\section{Introduction}

Cannabis is the most commonly used recreational drug, especially among teens and young adults [1]. Cannabis is primarily abused for its psychoactive effects, (eg, subjective euphoria, relaxation, and elevated mood), attributed to its main psychoactive constituent $\Delta^{9}$-tetrahydrocannabinol $\left(\Delta^{9}-\mathrm{THC}\right)$. Since the discovery of $\Delta^{9}$-THC, hundreds of novel analogues have been synthesized and used as therapeutic agents, as pharmacologic tools to enhance our understanding of the endocannabinoid system (see below), and most recently, as recreational drugs of abuse. Across the United States, commercial preparations of synthetic cannabinoids (SCBs) (eg, labeled "K2" or "Spice") have gained much attention among drug users and lawmakers. According to a 2012 survey, SCBs are the second-most commonly used illegal drug among young adults, with only cannabis use occurring at a higher rate [2]. In a 3-year product surveillance study in our state, 26 individual SCBs were detected in commercial products [3••]. The most common SCBs detected in Arkansas were JWH-018, AM2201, JWH122, JWH-210, and XLR11, and it was not uncommon to find 2 or 3 SCBs in combination in commercial products sold in the state [3・•]. Use of SCBs produces psychoactive effects similar to those of cannabis, they are easily accessible and difficult to detect in standard urine drug screens [4], which all contribute to their high rate of use. Despite local, state, and federal regulations of the more prevalent synthetic cannabinoids, SCB products can still be purchased with ease from the Internet, head shops, and convenience stores. Legislators are concerned with finding effective measures to curtail SCB availability, however, this has been particularly challenging given the constantly changing composition of commercial SCB products $[3 \bullet \bullet]$. This 
has also frustrated efforts at developing a standardized drug test that screens for SCB use.

Although commercial SCB products are typically sold as a mixture of plant materials (touted as "herbal incense" or "potpourri"), they have also been documented to exist as tablets, capsules, and as powders [3••]. According to the Drug Enforcement Administration (DEA), SCBs commonly found in commercial preparations include the aminoalkylindoles JWH-018, JWH-073, and JWH-200, and the cyclohexylphenols CP-47497 and CP-47497 C8, all of which are currently listed as Schedule I controlled substances [5]. Despite strict regulations on these particular SCBs, other analogs are still emerging in commercial products, including AKB48, AM-2201, JWH-081, JWH-122, UR-144, and XLR11 [6, 7]. Commercial preparations of SCBs often contain multiple combinations and varying concentrations of SCBs, even within products marketed with the same name and packaging, leading to marked dose/drug inconsistency from batch to batch $[8,9]$.

A strong motivation for controlling $\mathrm{SCBs,} \mathrm{in} \mathrm{addition} \mathrm{to}$ their cannabis-like intoxicating effects, is the relatively high incidence of adverse effects associated with their use, including acute psychosis, confusion, anxiety, tachycardia, drowsiness, dizziness, agitation, hypertension, seizures, convulsions, vomiting, nausea, high blood pressure and chest pain [10-13], acute central nervous system (CNS) and cardiovascular toxicity [14•], and long-term abuse-related effects of dependence and withdrawal $[15,16]$. According to the American Association of Poison Control Centers, there were 2906 reported cases of synthetic cannabinoid exposure in 2010, which more than doubled in 2011 to 6968 [17]. Amidst a flurry of media attention and strict legal regulations, exposures moderately decreased to 5228 in 2012 and 2639 in 2013 [17]. The implications of acute SCB use on human health remains poorly understood, and even less is known about the longterm effects of these drugs. Currently, there are no direct treatments for complications arising from SCB use, and only supportive care is provided in these cases.

Much of our understanding of commercial SCB products has primarily been achieved through studying the endocannabinoid system. Below, we briefly introduce the endocannabinoids to provide a background against which to compare the newly emerging SCB drugs of abuse. The remainder of this review will focus on current findings on the in vivo pharmacologic effects of synthetic cannabinoids, with a particular emphasis on their abuse potential.

\section{Endocannabinoid System}

The 1964 identification of the highly lipophilic $\Delta^{9}$-THC set the stage for the eventual discovery of the first cannabinoid (CB1) receptor in 1990, followed 3 years later by the characterization of the CB2-receptor $[18,19]$. Both $\mathrm{CB} 1$ and $\mathrm{CB} 2$ receptors are members of the 7 transmembrane $G$ protein coupled receptor (GPCR) superfamily [20]. CB1 receptors are among the most abundant GPCRs in the mammalian CNS. Outside the brain, CB1 receptors are expressed at lower levels in a variety of peripheral tissues including fat, heart, intestine, liver, endocrine, pancreas, and uterus [21]. CB2 receptors are primarily expressed in peripheral tissues, such as liver, lung, and kidney, and are closely associated with the immune and hematopoietic system [22, 23]. More recently, increasing evidence supports the existence of $\mathrm{CB} 2$ receptors in the brain, strengthening the idea of a functional significance of $\mathrm{CB} 2$ receptors in the CNS $[24,25]$. In this review, we will primarily focus on the effects of SCBs at CB1 receptors since they are primarily responsible for the abuserelated psychoactive effects of these drugs. The study of endocannabinoids is presently flourishing, and detailed reviews of endocannabinoid synthesis, signaling and metabolism are available [26-28].

\section{Cannabinoid Ligands}

There are 4 major chemical classes of exogenous cannabinoid ligands that differ structurally [29] (Fig. 1). Classical cannabinoids include $\Delta^{9}$-THC, AM2389, cannabinol, nabilone, HU-210, and other tricyclic terpenoid derivatives bearing a benzopyran moiety. Nonclassical cannabinoids include CP $55,940, \mathrm{HU}-308$, and other bicyclic and tricyclic analogs of $\Delta^{9}$-THC lacking the pyran ring of classical cannabinoids. Aminoalkylindoles including WIN55,212-2, JWH-018, JWH-073, and AM1241 differ in structure, lipophilicity, and binding activity at the cannabinoid receptors in comparison with the above-mentioned classes. Many of the aminoalkylindoles are currently found in commercial SCB products. Finally, 1,5 biarylpyrazole ligands act as cannabinoid receptor antagonists, and include compounds such as rimonabant and AM251, which are both CB1-receptor selective, and SR144528, which is CB2receptor selective.

\section{Preclinical In Vivo Pharmacology of Synthetic Cannabinoids}

Cannabinoid Tetrad

Administration of cannabinoid agonists from multiple structural classes elicits a characteristic cluster of effects in laboratory animals. This cluster of the 4 classical endpoints of hypothermia, analgesia, catalepsy, and locomotor suppression has been termed the cannabinoid tetrad [30,31]. Qualitatively consistent data are reliably observed for cannabinoid agonists across tetrad measures, characterized by dose-dependent decreases in measures of body temperature and motor activity, 
Fig. 1 Cannabinoid ligands. Representative compounds of the 4 major chemical classes of exogenous cannabinoid ligands. Note that the classical cannabinoid $\Delta^{9}$-THC is a relatively low efficacy partial agonist at cannabinoid receptors, the nonclassical cannabinoid $\mathrm{CP}$ 55,940 and the aminoalkylindole JWH-018 are both full agonists at $\mathrm{CB} 1$ receptors, while the 1,5 biarylpyrazole rimonabant functions as an antagonist / inverse agonist at cannabinoid receptors
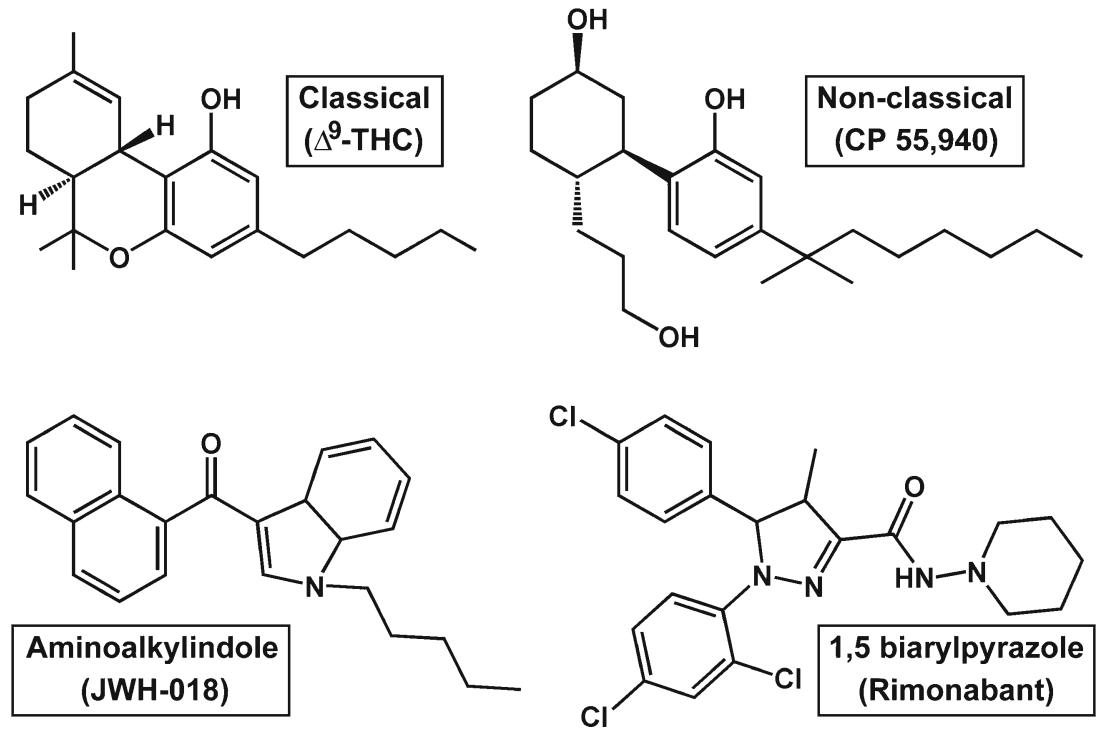

and dose-dependent increases in measures of analgesia and catalepsy. The advantage of using these tetrad measures to evaluate cannabinoids is that none of these assays require any particular training of the animals. Thus, data can be generated rapidly. Another advantage of the tetrad is that all of these endpoints can be assessed in quick succession in the same subject, decreasing total animal usage.

The cannabinoid tetrad has been extremely useful in the characterization of the biological activity of cannabinoid ligands. Interestingly, $\Delta^{9}$-THC tends to elicit tetrad effects of similar magnitude to higher efficacy cannabinoids such as WIN 55-212 and CP-55,940 [32]. The SCBs JWH-018 and JWH-073 also elicit characteristic tetrad effects in the mouse after intraperitoneal injection [33]. CB1-receptor mediated tetrad effects after exposure to smoke produced from combustion of an herbal incense product containing $5.4 \%$ JWH-018 have also been reported [34•]. Importantly, a Phase I hydroxylated JWH-018 metabolite retained marked cannabimimetic effects in vivo, eliciting profound hypothermic and locomotor depressant effects in mice, which were blocked by pretreatment with AM251, a CB1-receptor selective antagonist [35••]. Similarly, the analogous metabolite of JWH-073 also decreased core temperature and locomotor activity in the mouse [33]. However, not all biologically active Phase I hydroxylated metabolites of these compounds are cannabinoid agonists, as pretreatment with a different metabolite of JWH-073 significantly blunted hypothermic effects elicited by JWH-018 in the mouse without altering core temperature on its own [33]. Interestingly, this metabolite of JWH-073 did not alter the analgesic, cataleptic, or locomotor effects of JWH-018 in the mouse, perhaps suggesting that it did not penetrate the CNS at the dose tested [33].

Overall, the tetrad assay reveals that commercially available SCBs elicit effects similar to those of the prototypical cannabinoid $\Delta^{9}$-THC. Furthermore, these effects are believed to be CB1-receptor mediated since pretreatment with $\mathrm{CB} 1$ receptor antagonists can block these effects. Finally, the activity of Phase I metabolites of some common SCBs raises the intriguing possibility that genetic polymorphisms in cytochrome P450 enzymes may play an important role in determining an individual's response to these drugs. For example, an individual with a liver enzyme profile leading to biased production of antagonist metabolites might experience greatly attenuated drug effects, while an individual with a liver enzyme profile favoring formation of agonist metabolites might experience potentiated or longer-lasting drug effects.

\section{Discriminative Stimulus Effects}

Cannabinoids exert numerous effects on perception and other unobservable variables in humans, thus, drug discrimination is useful as a preclinical and clinical model of these subjective effects. The drug discrimination assay can be thought of as an in vivo procedure to identify drugs with similar subjective effects to a well-characterized training drug. Thus, when studying emerging SCB drugs of abuse, a dose of $\Delta^{9}-\mathrm{THC}$ is typically used as the standard training stimulus. Centrallyactive cannabinoid agonists reliably induce $\Delta^{9}$-THC-like effects in animals trained to discriminate $\Delta^{9}$-THC. For example, full substitution for $\Delta^{9}$-THC was observed with WIN 55212 and 1-butyl-2-methyl-3-(1-naphthoyl) indole in monkeys [36], and with R(-)-methanandamide in rats [37]. Thus, drug discrimination may be particularly useful in the study of cannabinoid in vivo pharmacology, both due to its high degree of pharmacologic specificity, and because results from preclinical studies are predictive of the subjective effects of cannabis in humans [38]. 
To date, only a few studies have examined the discriminative stimulus effects of SCBs present in commercial products. In rats, JWH-018 has been shown to substitute for $\Delta^{9}$-THC and for the endocannabinoid analogue methanandamide [39•, 40]. In these studies, consistent with in vitro data, JWH-018 was more potent than $\Delta^{9}$-THC and methanandamide, and the interoceptive effects of JWH-018 were attenuated by pretreatment of the CB1-receptor selective antagonist rimonabant. Similarly, in rhesus monkeys, JWH-018 and JWH-073 fully substituted for the discriminative stimulus effects of $\Delta^{9}$-THC, and antagonist studies with rimonabant suggest that they did so via interactions with CB1 receptors [41]. Most recently, novel tetramethylcyclopropyl ketone indoles currently emerging as drugs of abuse were tested for $\Delta^{9}$-THC-like discriminative effects in rats. As might be expected, both UR-144 and XLR-11 fully substituted for $\Delta^{9}$-THC, were more potent than $\Delta^{9}$-THC itself, and were antagonized by rimonabant pretreatment [42]. This provides further evidence that the subjective effects of SCBs are mediated through the CB1-receptor Table 1.

\section{Reinforcing Effects}

Assessment of the reinforcing effects of drugs is accomplished using the self-administration technique, in which an operant response results in the immediate administration of the drug. Despite recreational use and abuse of cannabinoids throughout human history, the reinforcing effects of cannabinoids have not been widely investigated in laboratory animals. Intravenous self-administration of low $\Delta^{9}$-THC doses were demonstrated in squirrel monkeys [44, 45]. Furthermore, reports have shown that high efficacy cannabinoids WIN 55,512 and HU-210, both found in some SCB commercial products, maintain intravenous self-administered behavior in mice and rats [46-48]. These data may suggest that other high efficacy cannabinoids, such as those SCBs present in commercial products, might also display reinforcing effects in selfadministration procedures, but thus far, no published reports bolster this supposition. Importantly, the reports in squirrel monkeys and rats demonstrate that the reinforcing effects of intravenous cannabinoids are significantly attenuated by pretreatment with CB1-receptor antagonists, strongly suggesting that the abuse-related effects of these substances are indeed mediated by central cannabinoid systems.

\section{Conditioned Place Preference}

Another way to indirectly assess abuse-related effects of cannabinoids in experimental animals is to study their capacity to elicit a conditioned place preference. Studies investigating the capacity of cannabinoids to induce conditioned place preference present a complex and contradictory picture, which is discussed in detail elsewhere [49]. Nevertheless, robust preferences for $\Delta^{9}$-THC-paired contexts have sometimes been reported in rats [50] and mice [51-53] under carefully controlled experimental conditions. Recently, it was demonstrated that the SCB JWH-018 induced a dose-dependent place aversion in previously drug-naïve mice, but elicited place preference in mice with a history of $\Delta^{9}$-THC administration [54]. This finding, coupled with the fact that place preference

Table 1 Synthetic compounds found in commercial products

\begin{tabular}{llll}
\hline Compound & CB1 affinity Ki (nM) & CB1 affinity (x THC) & Reference \\
THC & 15.29 & - & 12.53 \\
JWH-018 & 1.22 & 38.71 \\
AM-2201 & 0.40 & - & {$[35 \cdot \bullet, 43]$} \\
THC & 67.00 & 2.79 \\
UR-144 & 24.00 & 2.31 \\
XLR-11 & 29.00 & CB1 efficacy $(\%$ CP) \\
Compound & CB1 efficacy EC E0 $_{50}(\mathrm{nM})$ & - \\
CP55,940 & 3.36 & 100 \\
JWH-018 & 6.82 & 100 \\
AM-2201 & ND & - \\
CP55,940 & 25.00 & 100 \\
UR-144 & 159.00 & 100 \\
XLR-11 & 98.00 & Reference \\
\hline
\end{tabular}

Affinity constants $\left(\mathrm{K}_{\mathrm{i}}\right)$ and estimates relative to $\Delta^{9}$ - THC (top) and efficacy $\left(\mathrm{EC}_{50}\right)$ at $\mathrm{CB} 1$ receptors and estimates relative to the standard $\mathrm{CB} 1$ full agonist CP55,940 (bottom) at CB1 for SCBs JWH-018, AM-2201, UR-144, and XLR-11. Lower $\mathrm{K}_{\mathrm{i}}$ values indicate higher affinity for the CB1 receptor. An efficacy equivalent $(100 \%)$ to that of CP indicates full agonist effects at the CB1 receptor. Brents et al (2011) and Chimalakonda et al (2012) data were obtained in mouse whole-brain homogenates, while data from Wiley et al (2013) were obtained from human cloned CB1 membranes. Assay conditions among laboratories will lead to variability in measures when the same compounds are tested, but the pattern of results is always the same: the $\mathrm{SCBs}$ in commercial preparations have higher affinity for $\mathrm{CB} 1$ receptors than $\Delta^{9}$ - THC, and exhibit full agonist efficacy 
induced by either $\Delta^{9}$-THC [55] or CP 55,940 [56] is attenuated by pretreatment of CB1-receptor antagonists, again implies that augmentation of cannabinoid signaling can lead to conditioned rewarding effects in rodents.

\section{Tolerance, Dependence, and Withdrawal}

Cannabinoid administration may lead to rapid tolerance to antinociceptive effects, anticonvulsant activity, cataleptic effects, suppression of locomotor activity hypothermia, hypotension, release of corticosteroids, and other effects in multiple species [57]. However, tolerance does not develop to all cannabinoid effects, eg, $\Delta^{9}$-THC-elicited adrenocorticotropic hormone (ACTH) secretion remained remarkably stable across 5 daily administrations in the rat [58]. Receptor theory states that tolerance to drug effects produced by treatment with a low efficacy ligand can be at least partially surmounted by administration of a high efficacy agonist, while tolerance to effects induced by repeated treatment with a high efficacy compound will elicit profound cross-tolerance when low efficacy ligands are tested. However, applying this theory of intrinsic efficacy in tolerance and cross-tolerance to cannabinoids is unreliable. In other words, a similar degree of tolerance to the hypothermic effects of $\Delta^{9}$-THC, a low efficacy cannabinoid agonist, CP-55,940 and WIN 55,212, both full efficacy cannabinoid agonists, was reported following chronic $\Delta^{9}$-THC administration, despite the substantial efficacy differences between these drugs [59]. However, a different regimen of $\Delta^{9}$-THC resulted in dramatic tolerance to $\Delta^{9}$-THC effects on locomotor activity, hypothermia, and antinociception in mice. Nevertheless, only moderate cross-tolerance was apparent when high efficacy agonists CP-55,940 or WIN 55,212 were tested, and only to some of these effects [32]. Furthermore, $\Delta^{9}$-THC treatment decreased sensitivity to the discriminative stimulus effects of $\Delta^{9}$-THC in rhesus monkeys, but did not alter the $\Delta^{9}$-THC-like interoceptive effects of high efficacy cannabinoids CP-55,940, JWH-073, or JWH-018 [60]. These apparent differences in tolerance to some behavioral and physiological effects are also reflected at the receptor level, as chronic administration of $\Delta^{9}$-THC or WIN 55212-2 resulted in similar levels of tolerance to drug-elicited hypoactivity, hypothermia, and antinociception, but a greater degree of CB1-receptor desensitization was quantified in the $\Delta^{9}$-THCtreated mice in some brain areas (eg, cerebellum amygdala, nucleus accumbens, and hippocampus) despite the substantially lower CB1-receptor efficacy [61]. A better understanding of the relationship between tolerance to in vivo effects and regulation of expression and function of $\mathrm{CB} 1$ receptors after chronic administration of cannabinoid agonists with varying efficacies is needed.

Drug dependence is not directly observable in vivo, rather it is assumed to be present when either the discontinuation of drug administration (spontaneous withdrawal) or the administration of an antagonist (precipitated withdrawal) elicits a withdrawal syndrome. The lack of a reliable and readily observed spontaneous withdrawal syndrome after discontinuation of $\Delta^{9}$-THC has caused much debate on the clinical relevance of cannabis withdrawal in humans. However, the terminology "cannabis withdrawal syndrome" has gained acceptance as described by the Diagnostic and Statistical Manual of Mental Disorders [62], and clinical reports of sleep disturbances, strange dreaming, decreased appetite, irritability, anxiety, depressed mood, physical discomfort, and drug cravings are said to occur as a result of discontinuation of cannabis use [63, 64]. WIN55,212-2, an aminoaklylindole SCB, which acts as a full agonist at $\mathrm{CB} 1$ receptors, elicited measurable signs of spontaneous withdrawal in rats [65]. In addition to the higher intrinsic efficacy, WIN55,212-2 is also eliminated more readily from adipose tissue due to its low lipophilicity, in comparison to $\Delta^{9}$-THC, which is stored and eliminated at a slower rate. One might speculate that the structurally related aminoalkylindole SCBs present in commercial preparations (JWH-018, AM2201, etc) might also elicit a cannabinoid withdrawal syndrome after abrupt discontinuation. To date, there are no preclinical data to directly support this notion, but clinical reports suggest a relatively high incidence of withdrawal in frequent/daily users of $\mathrm{K} 2$ and Spice products. The withdrawal syndrome elicited after abrupt discontinuation of SCBs is similar to reports with $\Delta^{9}$-THC, and consists of chills, drug cravings, headaches, insomnia, anorexia, inner unrest, nausea, and nocturnal nightmares, but also includes potentially more severe symptoms such as seizures and hallucinations $[6,15,16]$. Interestingly, Gunderson and colleagues recently reported that the psychoactive effects of commercial SCB preparations substituted for those of cannabis in cannabisdependent patients, and also blocked or attenuated cannabis withdrawal syndrome in these same patients [14•].

\section{Conclusions}

Much of our understanding of cannabinoid tolerance, dependence, and withdrawal has been based on studies involving $\Delta^{9}$-THC, a relatively weak partial agonist at CB1 and CB2 receptors. However, the SCBs commonly found in quasi-legal commercial products, such as K2 and Spice, are typically full cannabinoid receptor agonists. Importantly, a drug's efficacy determines how "powerful" its maximal effects may be in biological systems. A low efficacy cannabinoid like $\Delta^{9}$-THC will have a less pronounced maximal effect than a higher efficacy cannabinoid, such as the SCBs present in commercial products, and this difference in maximal effects cannot be overcome simply by increasing the dose of $\Delta^{9}$-THC. In other words, no amount of $\Delta^{9}$-THC can stimulate cannabinoid receptors to the same degree as the SCBs currently emerging 
as drugs of abuse. This has left researchers working with these high efficacy SCBs in the unusual position of having to determine whether their effects are related to the unprecedented degree of cannabinoid receptor stimulation elicited by these compounds, or whether they are produced by interactions with other, noncannabinoid receptor systems.

In light of the growing popularity of commercial SCB products, it has become critically important to re-evaluate our understanding of cannabinoid abuse. Increasing evidence suggests that there is a strong abuse potential for the high efficacy SCBs, at least comparable to that of cannabis itself. Furthermore, these SCB products are readily accessible and can be purchased easily from the comfort of home through the Internet. As long as there is a market for SCBs, competitive pricings and attractive gimmicks will be used to increase sales. Given the prevalence of SCB consumption, there is an urgent need to better understand the pharmacology and toxicology of synthetic cannabinoids. In particular, the role of intrinsic efficacy in abuse-related effects and adverse effects should be targeted in future studies. Finally, commercial SCB products can no longer be viewed as innocuous alternatives to cannabis. Instead, the profound psychoactive effects of these preparations must be recognized and acknowledged to result from the combined actions of a complex mixture of different SCBs present in commercial preparations, almost all of which are more efficacious than $\Delta^{9}$-THC.

\section{Compliance with Ethics Guidelines}

Conflict of Interest S. Tai and W. E. Fantegrossi declare that they have no conflict of interest.

Human and Animal Rights and Informed Consent This article does not contain any studies with human or animal subjects performed by any of the authors.

\section{References}

Papers of particular interest, published recently, have been highlighted as:

- Of importance

•- Of major importance

1. Substance Abuse and Mental Health Services Administration, Results from the 2012 National Survey on Drug Use and Health: Summary of National Findings. NSDUH Series H-46, HHS Publication No. (SMA) 13-4795. Rockville, MD; 2013.

2. Johnston LD, O'Malley PM, Bachman JG, Schulenberg JE. The rise in teen marijuana use stalls, synthetic marijuana use levels, and use of 'bath salts' is very low. University of Michigan News Service: Ann Arbor, MI. Retrieved 09/24/2013 from http://www. monitoringthefuture.org, 2012.

3.• Seely KA, Patton AL, Moran CL, Womack ML, Prather PL, Fantegrossi WE, et al. Forensic investigation of K2, Spice, and "bath salt" commercial preparations: A three-year study of new designer drug products containing synthetic cannabinoid, stimulant, and hallucinogenic compounds. Forensic Sci Int. 2013. 233(13): p. 416-22. This study details efforts to track the compositions of commercial SCB products in the state of Arkansas over a three-year period during which several major state and federal legislative changes aimed at controling the proliferation of these substances were enacted. The major psychoactive constituents on commercial SCB products are described, as are the effects of legislation on drug availability.

4. Auwarter V, Dresen S, Weinmann W, Muller M, Putz M, Ferreiros N. 'Spice' and other herbal blends: harmless incense or cannabinoid designer drugs? J Mass Spectrom. 2009;44(5):832-7.

5. Drug Enforcement Administration. Schedules of controlled substances: temporary placement of five synthetic cannabinoids into Schedule I. Microgram Bulletin, 2011. 44(3): 21-30.

6. Musshoff F, Madea B, Kernbach-Wighton G, Bicker W, Kneisel S, Hutter M, et al. Driving under the influence of synthetic cannabinoids ("Spice"): a case series. Int J Leg Med. 2014;128:59-64.

7. Drug Enforcement Administration. Schedules of controlled substances: temporary placement of three synthetic cannabinoids into Schedule I. Final order. Fed Regist. 2013. 78(95): 28735-9.

8. Lindigkeit R, Boehme A, Eiserloh I, Luebbecke M, Wiggermann M, Ernst L, et al. Spice: a never ending story? Forensic Sci Int. 2009;191(1-3):58-63.

9. Piggee C. Investigating a not-so-natural high. Anal Chem. 2009;81(9):3205-7.

10. Every-Palmer S. Synthetic cannabinoid JWH-018 and psychosis: an explorative study. Drug Alcohol Depend. 2011;117(2-3):152-7.

11. Forrester MB. Adolescent synthetic cannabinoid exposures reported to Texas poison centers. Pediatr Emerg Care. 2012;28(10):9859.

12. Pant S, Deshmukh A, Dholaria B, Kaur V, Ramavaram S, Ukor M, et al. Spicy seizure. Am J Med Sci. 2012;344(1):67-8.

13. Schneir AB, Baumbacher T. Convulsions associated with the use of a synthetic cannabinoid product. J Med Toxicol. 2012;8(1):62-4.

14. Gunderson EW, Haughey HM, Ait-Daoud N, Joshi AS, Hart CL. "Spice" and "K2" herbal highs: a case series and systematic review of the clinical effects and biopsychosocial implications of synthetic cannabinoid use in humans. Am J Addict. 2012. 21(4): p. 320-6. Several cases of SCB use among THC-dependent subjects are described. The fact that SCBs prevent or alleviate THC withdrawal implies that these drugs are likely to share a common site and mechanism of action.

15. Nacca N, Vatti D, Sullivan R, Sud P, Su M, Marraffa J. The synthetic cannabinoid withdrawal syndrome. J Addict Med. 2013;7(4):296-8.

16. Zimmermann US, Winkelmann PR, Pilhatsch M, Nees JA, Spanagel R, Schulz K. Withdrawal phenomena and dependence syndrome after the consumption of "spice gold". Dtsch Arztebl Int. 2009;106(27):464-7.

17. American Association of Poison Control Centers. Synthetic Marijuana Data. Retrieved 02/10/2013 from http://www.aapcc. org/alerts/synthetic-marijuana/, 2013.

18. Howlett AC, Barth F, Bonner TI, Cabral G, Casellas P, Devane WA, et al. International Union of Pharmacology. XXVII. Classification of cannabinoid receptors. Pharmacol Rev. 2002;54(2):161-202.

19. Montero C, Campillo NE, Goya P, Páez JA. Homology models of the cannabinoid $\mathrm{CB} 1$ and $\mathrm{CB} 2$ receptors. A docking analysis study. Eur J Med Chem. 2005;40(1):75-83.

20. Begg M, Pacher P, Batkai S, Osei-Hyiaman D, Offertaler L, Mo FM, et al. Evidence for novel cannabinoid receptors. Pharmacol Ther. 2005;106(2):133-45.

21. Tucci SA, Halford JC, Harrold JA, Kirkham TC. Therapeutic potential of targeting the endocannabinoids: implications for the treatment of obesity, metabolic syndrome, drug abuse and smoking cessation. Curr Med Chem. 2006;13(22):2669-80. 
22. Munro S, Thomas KL, Abu-Shaar M. Molecular characterization of a peripheral receptor for cannabinoids. Nature. 1993;365(6441): $61-5$.

23. Teixeira-Clerc F, Julien B, Grenard P, Tran Van Nhieu J, Deveaux $\mathrm{V}$, Hezode $\mathrm{C}$, et al. The endocannabinoid system as a novel target for the treatment of liver fibrosis. Pathol Biol. 2008;56(1):36-8.

24. Garcia-Gutierrez MS, Garcia-Bueno B, Zoppi S, Leza JC, Manzanares J. Chronic blockade of cannabinoid CB2 receptors induces anxiolytic-like actions associated with alterations in GABA(A) receptors. Br J Pharmacol. 2012;165(4):951-64.

25. Xi ZX, Peng XQ, Li X, Song R, Zhang HY, Liu QR, et al. Brain cannabinoid $\mathrm{CB}(2)$ receptors modulate cocaine's actions in mice. Nat Neurosci. 2011;14(9):1160-6.

26. Grotenhermen F. Pharmacology of cannabinoids. Neuro Endocrinol Lett. 2004;25(1-2):14-23.

27. Di Marzo V, De Petrocellis L. Why do cannabinoid receptors have more than one endogenous ligand? Philos Trans Roy Soc Lond B, Biol Sci. 2012;367(1607):3216-28.

28. Pertwee RG. Targeting the endocannabinoid system with cannabinoid receptor agonists: pharmacological strategies and therapeutic possibilities. Philos Trans Roy Soc Lond B, Biol Sci. 2012. 367(1607): p. 3353-63.

29. Palmer SL, Thakur GA, Makriyannis A. Cannabinergic ligands. Chem Phys Lipids. 2002;121(1-2):3-19.

30. Compton DR, Johnson MR, Melvin LS, Martin BR. Pharmacological profile of a series of bicyclic cannabinoid analogs: classification as cannabimimetic agents. J Pharmacol Exp Ther. 1992;260(1):201-9.

31. Little PJ, Compton DR, Johnson MR, Melvin LS, Martin BR. Pharmacology and stereoselectivity of structurally novel cannabinoids in mice. J Pharmacol Exp Ther. 1988;247(3):1046-51.

32. Fan F, Compton DR, Ward S, Melvin L, Martin BR. Development of cross-tolerance between delta-9-tetrahydrocannabinol, CP 55, 940 and WIN 55,212. J Pharmacol Exp Ther. 1994;271(3):138390.

33. Brents LK, Gallus-Zawada A, Radominska-Pandya A, Vasiljevik T, Prisinzano TE, Fantegrossi WE, et al. Monohydroxylated metabolites of the K2 synthetic cannabinoid JWH-073 retain intermediate to high cannabinoid 1 receptor (CB1R) affinity and exhibit neutral antagonist to partial agonist activity. Biochem Pharmacol. 2012;83(7):952-61.

34. Wiebelhaus JM, Poklis JL, Poklis A, Vann RE, Lichtman AH, Wise LE. Inhalation exposure to smoke from synthetic "marijuana" produces potent cannabimimetic effects in mice. Drug Alcohol Depend. 2012. 126(3): 316-23. This is the first demonstration that cannabimimetic effects of a commercial SCB product are induced in mice after "smoking." All of the in vivo endpoints of the cannabinoid tetrad are utilized, and these effects are blunted in mice previously administered a CB1 antagonist.

35.• Brents LK, Reichard EE, Zimmerman SM, Moran JH, Fantegrossi WE, Prather PL. Phase I hydroxylated metabolites of the K2 synthetic cannabinoid JWH-018 retain in vitro and in vivo cannabinoid 1 receptor affinity and activity. PLoS One. 2011. 6(7): e21917. This paper assesses CB1 receptor affinity and efficacy for a number of hydroxylated Phase I metabolistes of the SCB JWH-018. In vitro, it is shown that many of these metabolites retain high affinity for the $C B 1$ receptor, and exhibit a range of efficacies from full agonism to antagonism. In vivo, one of these metabolites elicits hypothermic effects via activation of $C B 1$ receptors. The formation of these active metabolites will likely differ among individuals as a function of CPY450 polymorphisms, and may be a mechanism for toxicity in some individuals.

36. Wiley JL, Huffman JW, Balster RL, Martin BR. Pharmacological specificity of the discriminative stimulus effects of delta 9-tetrahydrocannabinol in rhesus monkeys. Drug Alcohol Depend. 1995;40(1):81-6.
37. Jarbe TU, Lamb RJ, Lin S, Makriyannis A. (R)-methanandamide and Delta 9-THC as discriminative stimuli in rats: tests with the cannabinoid antagonist SR-141716 and the endogenous ligand anandamide. Psychopharmacology (Berl). 2001. 156(4): 369-80.

38. Balster RL, Prescott WR. Delta 9-tetrahydrocannabinol discrimination in rats as a model for cannabis intoxication. Neurosci Biobehav Rev. 1992;16(1):55-62.

39. Jarbe TU, Deng H, Vadivel SK, Makriyannis A. Cannabinergic aminoalkylindoles, including AM678=JWH018 found in 'Spice', examined using drug (Delta(9)-tetrahydrocannabinol) discrimination for rats. Behav Pharmacol. 2011. 22(5-6): 498-507. The experiments described in this report highlight the utility of the drug discrimination procedure in the study of emerging SCBS.

40. Jarbe TU, Vadivel SK, Makriyannis A. Discriminative stimulus functions of methanandamide and delta(9)-THC in rats: tests with aminoalkylindoles (WIN55,212-2 and AM678) and ethanol. Psychopharmacology (Berl). 2010;208(1):87-98.

41. Ginsburg BC, Schulze DR, Hruba L, McMahon LR. JWH-018 and JWH-073: Delta(9)-tetrahydrocannabinol-like discriminative stimulus effects in monkeys. J Pharmacol Exp Ther. 2012;340(1):3745.

42. Wiley JL, Marusich JA, Lefever TW, Grabenauer M, Moore KN, Thomas BF. Cannabinoids in disguise: Delta(9)Tetrahydrocannabinol-like effects of tetramethylcyclopropyl ketone indoles. Neuropharmacology. 2013;75:145-54.

43. Chimalakonda KC, Seely KA, Bratton SM, Brents LK, Moran CL, Endres GW, et al. Cytochrome P450-mediated oxidative metabolism of abused synthetic cannabinoids found in K2/Spice: identification of novel cannabinoid receptor ligands. Drug Metab Dispos. 2012;40(11):2174-84.

44. Justinova Z, Tanda G, Redhi GH, Goldberg SR. Self-administration of delta9-tetrahydrocannabinol (THC) by drug naive squirrel monkeys. Psychopharmacology (Berl). 2003;169(2):135-40.

45. Tanda G, Munzar P, Goldberg SR. Self-administration behavior is maintained by the psychoactive ingredient of marijuana in squirrel monkeys. Nat Neurosci. 2000;3(11):1073-4.

46. Fattore L, Cossu G, Martellotta CM, Fratta W. Intravenous selfadministration of the cannabinoid CB1 receptor agonist WIN 55, 212-2 in rats. Psychopharmacology (Berl). 2001;156(4):410-6.

47. Martellotta MC, Cossu G, Fattore L, Gessa GL, Fratta W. Selfadministration of the cannabinoid receptor agonist WIN 55,212-2 in drug-naive mice. Neuroscience. 1998;85(2):327-30.

48. Navarro M, Carrera MR, Fratta W, Valverde O, Cossu G, Fattore L, et al. Functional interaction between opioid and cannabinoid receptors in drug self-administration. J Neurosci. 2001;21(14):5344-50.

49. Justinova Z, Goldberg SR, Heishman SJ, Tanda G. Self-administration of cannabinoids by experimental animals and human marijuana smokers. Pharmacol Biochem Behav. 2005;81(2):285-99.

50. Lepore M, Vorel SR, Lowinson J, Gardner EL. Conditioned place preference induced by delta 9-tetrahydrocannabinol: comparison with cocaine, morphine, and food reward. Life Sci. 1995;56(2324):2073-80.

51. Castane A, Robledo P, Matifas A, Kieffer BL, Maldonado R. Cannabinoid withdrawal syndrome is reduced in double mu and delta opioid receptor knockout mice. Eur J Neurosci. 2003;17(1): $155-9$

52. Valjent E, Maldonado R. A behavioural model to reveal place preference to delta 9-tetrahydrocannabinol in mice. Psychopharmacology (Berl). 2000;147(4):436-8.

53. Valjent E, Mitchell JM, Besson MJ, Caboche J, Maldonado R. Behavioural and biochemical evidence for interactions between Delta 9-tetrahydrocannabinol and nicotine. Br J Pharmacol. 2002;135(2):564-78.

54. Hyatt WS, Fantegrossi WE. Delta-9-THC exposure attenuates aversive effects and reveals appetitive effects of K2/"Spice" constituent JWH-018 in mice. Behav Pharmacol. 2014. in press. 
55. Braida D, Iosue S, Pegorini S, Sala M. Delta9-tetrahydrocannabinol-induced conditioned place preference and intracerebroventricular self-administration in rats. Eur J Neurosci. 2004;506(1):63-9.

56. Braida D, Pozzi M, Cavallini R, Sala M. Conditioned place preference induced by the cannabinoid agonist CP 55,940: interaction with the opioid system. Neuroscience. 2001;104(4):923-6.

57. Adams IB, Martin BR. Cannabis: pharmacology and toxicology in animals and humans. Addiction. 1996;91(11):1585-614.

58. Dewey WL, Peng TC, Harris LS. The effect of 1-trans-delta 9tetrahydrocannabinol on the hypothalamo-hypophyseal-adrenal axis of rats. Eur J Pharmacol. 1970;12(3):382-4.

59. Pertwee RG, Stevenson LA, Griffin G. Cross-tolerance between delta-9-tetrahydrocannabinol and the cannabimimetic agents, CP 55,940, WIN 55,212-2 and anandamide. Br J Pharmacol. 1993;110(4):1483-90.

60. Hruba L, Ginsburg BC, McMahon LR. Apparent inverse relationship between cannabinoid agonist efficacy and tolerance/cross-tolerance produced by Delta(9)-tetrahydrocannabinol treatment in rhesus monkeys. J Pharmacol Exp Ther. 2012;342(3):843-9.
61. Sim-Selley LJ, Martin BR. Effect of chronic administration of R-(+ )-[2,3-Dihydro-5-methyl-3-[(morpholinyl)methyl]pyrrolo[1,2,3de]-1,4-benzoxaz inyl]-(1-naphthalenyl)methanone mesylate (WIN55,212-2) or delta(9)-tetrahydrocannabinol on cannabinoid receptor adaptation in mice. J Pharmacol Exp Ther. 2002;303(1): 36-44.

62. American Psychiatric Association: Diagnostic and Statistical Manual of Mental Disorders, 4th Edition, Text Revision. Washington, DC, American Psychiatric Association, 2000.

63. Allsop DJ, Copeland J, Norberg MM, Fu S, Molnar A, Lewis J, et al. Quantifying the clinical significance of cannabis withdrawal. PLoS One. 2012;7(9):e44864.

64. Allsop DJ, Norberg MM, Copeland J, Fu S, Budney AJ. The Cannabis Withdrawal Scale development: patterns and predictors of cannabis withdrawal and distress. Drug Alcohol Depend. 2011;119(1-2):123-9.

65. Aceto MD, Scates SM, Martin BB. Spontaneous and precipitated withdrawal with a synthetic cannabinoid, WIN 55212-2. Eur J Pharmacol. 2001;416(1-2):75-81. 